\title{
Introducing Economic Order Quantity Model for Inventory Control in Web based Point of Sale Applications and Comparative Analysis of Techniques for Demand Forecasting in Inventory Management
}

\author{
Komal Nain Sukhia, Aliya Ashraf Khan, Mukhtiar Bano \\ Department of Software Engineering, Fatima Jinnah Women University, Rawalpindi, Pakistan
}

\begin{abstract}
This paper has primary focus on the aspect of inventory management in web based point of sale applications for supermarkets. The major research focus include selection of efficient technique for demand forecasting in retail industry, the introduction of Economic Order Quantity model to reduce the overall inventory related costs and stock-out, analyzing customer transactions to improve sales, determining product shelving and supplier selection. For this purpose, Economic Order Quantity model is applied on the forecasted demands using simple moving average, linear regression, back propagation algorithm and afterwards a comparative analysis is conducted on the basis of costs generated by each demand forecasting technique. The comparison shows that back propagation algorithm is more efficient for demand forecasting and the overall inventory costs after applying Economic Order Quantity model are found to be lowest for back propagation algorithm as compared to the Linear Regression and Simple Moving Average.
\end{abstract}

\section{Keywords}

Apriori Algorithm, Back Propagation Algorithm, Data mining, Economic Order Quantity model, K-means Algorithm, Linear Regression, Naïve Bayesian Algorithm

\section{INTRODUCTION}

Point of sale (POS) or checkout describes a place of retail transaction occurrence. It is a point where a customer pays a merchant in return of goods or items bought. At the point of sale merchant can adopt the methods such as a manual system, barcode scanners, and electronic cash registers and touch screen displays to calculate the amount owing and to complete the transaction. Moreover, the merchant also issues a receipt for the transaction. The POS is customized by retail industry based on varied needs of small and medium sized retailers. Example can be a grocery store that may require a weighing scale at the point of sale, while restaurants may use automated computerized systems. The modern point of sale must include advanced functionalities such as inventory management, CRM (customer relation management), financials, warehousing, etc. Before the advent of the latest POS, all of the functions like inventory management, financials, warehousing were done independently and manually, which resulted in a lot of errors. The early cash registers were made in proprietary software and they had limited functions. Later, point of sale software was used to receive customer orders at the restaurant's entrance, and printing the preparation details in the kitchen. Such an intelligent process enabled customers to go to their tables where they can find the food already prepared for them. This software had an enhancement as compared to previous one as it also contained real time labor and food cost reports. With more technology advancements, points of sale applications are becoming common. Therefore, there is a need of incorporating advanced functionalities in a point of sale to cater different needs, like inventory is essential to keep up the pace with technological modernization and increasing retail management demands. Inventory management and inventory control is required to confirm control of quality in businesses in order to manage the transactions that focus consumer purchases. Without handling inventory control efficiently, large retail stores like Wal-Mart or JC Penny may face stockout on an important product. In short, effective inventory control system will be able to alert the retailer at the reorder time.

\subsection{Problem Description}

Due to today's uncertain economy, companies are trying to adopt alternative ways to remain competitive. Different ineffective forecasting methods lead to multiple product stock outs. So research revolves around different forecasting techniques for demand prediction and determining what will be the optimal quantity of inventory to order and when it should be ordered so that out of stock inventory problems can be avoided.

\subsection{Research Methodology}

The proposed application can determine order quantity, reordering point, product shelving, inventory categorization and supplier selection mainly by using data mining techniques. The point of sale application can manage daily transactions and maintain record of customers, inventory and employees. The historical quarterly sales data for different products is saved in database so that sales behavior can be analyzed and to establish a forecasting trend for each product.

\subsubsection{Main Tasks}

- Demand forecast is done on the basis of three techniques namely Simple Moving Average, Linear Regression and Back Propagation.

- Apriori algorithm is used to analyze customer transactional data to determine which products are likely to be bought together in order to solve product shelving issues.

- Inventory Categorization (ABC Classification) is done by using $\mathrm{K}-$ means algorithm to figure out the products that are critical to control for effective inventory management.

- Knowledge base is maintained for supplier selection based on given criteria. 
- An inventory control model i.e. Economic Order Quantity model is used. The predicted demand is used in Economic Order Quantity model which calculates optimum order quantity and reorder points for each product. At last comparison is done between the three technique results on the basis of cost saving.

The research paper is structured as follows - Section 2 begins with literature review. Section 3 addresses implementation of proposed application. Section 4 presents the results. Section 5 is about conclusion and future work.

\section{LITERATURE REVIEW}

Karthik Sundararaman et al. in [1] employed Baseline prediction as a means to present the marketing strategy for consumer goods. According to paper, in order to generate baseline for future techniques like Simulation techniques and time series algorithms are used. The algorithm that is suitable for a particular point of sales data changes depending on the datasets. POS data for the consumer goods of a store is introduced for a period of two years depending on the types of promotion, duration of occurrence and other requirements. Two methods are used to analyze the POS data. 1) Forecasting by combining Seasonal Adjustment and Linear Exponential Smoothening 2) Winters Model. The baseline prediction is for a period of one year. Results demonstrate that winters model is a better fit for the point of sales data used for testing purpose than LES model.

Further, Numera Tahir et al. in [2] devised a decision support system that contains three different analysis methods which are: Price based Analysis; Quantity based Analysis and ABC Analysis. The research involves extension of the proposed decision support system to a gas plant inventory and a comparative analysis is conducted for the former two methods to separate the critical parts on the basis of their price and quantity respectively. Main inputs include the inventory, their price and quantity consumed. These inputs are then used by DSS to figure out the critical items based on price, quantity, annual cost separately and subsequently critical items considering all three components together. The results describe that according to price based analysis, $85.7 \%$ of revenue is used by $1.25 \%$ of the items. Whereas $10.1 \%$ by $8.45 \%$ and $4.2 \%$ by $90.3 \%$ of the items. In the quantity based analysis, $0.33 \%$ of revenue is used by $33.01 \%$ of the total items, $0.76 \%$ by $33.33 \%$ and $98.89 \%$ by only $33.66 \%$ of the total items. ABC analysis shows that $23 \%$ of items make $60 \%$ of annual cost whereas $36 \%$ of items make $22 \%$ of annual costs and $41 \%$ of items make $18 \%$ contribution to annual costs. Overall results show that almost $20 \%$ of the items make major amount of budget. For these $20 \%$ critical items, inventory costs must be decreased.

Yunkang Yue et al. in [3] presented that due to transformation in consumption conception, supermarkets invested a lot on constructing and applying the Information technology, the major aspects include barcode, POS and database technology, etc. Trade information is recorded still its utilization is unsatisfactory. For this, new technology i.e. Data Mining, is used by the supermarket administration which changes management of supermarket to knowledge management. Data mining finds its application in supermarkets, where business handling can be done with POS, customer's information can be collected and sales data can be accumulated. Paper describes data mining applications in supermarkets to major aspects like analyzing consumption behavior, commodities reconfiguration, enhancing customer's relationship etc.
Qizhi Wu et al. in [4] in his research conducted an analysis of three models based on economic order quantity (EOQ) model in order to reduce inventory costs of items sold in one of the Carrefour supermarket outlets. Paper describes three models which are: 1. model with lots ordered and delivered separately, 2. model with lots ordered and delivered together, and 3. model with lots ordered and delivered for specific subset. These three models are discussed and mathematically compared in this paper. The third model includes greater specific procedures which can lead to an optimal solution due to its lowest cost.

Pradip Kumar Bala et al. in [5] argue that minimum error for demand forecast lead to success in supply chain management. With the advent of data mining systems, business intelligence has been introduced in varied domains of retail and business. The current paper attempts to describe the classification of the customers using decision tree approach which further acts as an input to the demand forecasting. The paper proposes a forecasting model based on decision tree approach for making demand forecast better and to improve the inventory performance in supply chain. The proposed forecasting model with the inventory replenishment system resulted in enhanced customer service level and reduction in inventory level.

Goswami D.N.* et al. in [6] presented that frequent pattern mining has large number of applications in data mining field. Frequent pattern mining from large databases results in an important problem in data mining. Apriori algorithm is firstly proposed in this field. With the passage of time Apriori algorithm has undergone various changes to enhance the performance. In this paper three different frequent pattern mining approaches: Record filter, Intersection and Proposed Algorithm are discussed which are based on Apriori algorithm. The findings of this paper are that the proposed algorithm performs better than other frequent pattern mining algorithm.

\section{IMPLEMENTATION OF PROPOSED APPLICATION}

The proposed point of sale application is designed specifically for the supermarket, for which the main features of inventory management, inventory control, real-time sales and purchase orders are considered. The order quantity and Reorder level is determined by using the EOQ (Economic Order Quantity) Model. This model can help to determine what would be the optimal order quantity along with limiting the inventory related costs (Holding cost, Ordering Cost) to minimum. Similarly Reorder point would determine the sufficient stock at hand in order to satisfy the customer demand till the next order arrives. The design of the proposed application is shown in Fig. 1:

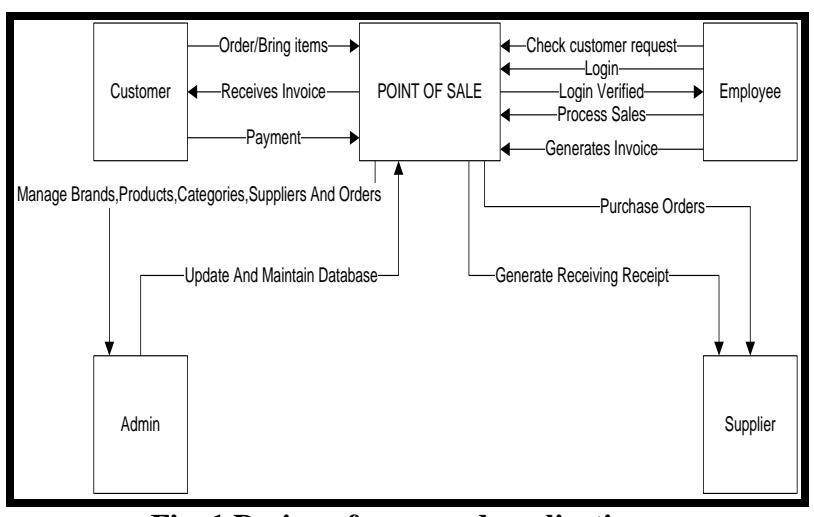

Fig. 1 Design of proposed application 
Main objectives of application are described as:

\subsection{Demand Forecasting}

The demand forecast is done using statistical i.e. moving average and data mining techniques i.e. linear regression and back propagation and the parameters used in each technique for forecast are:

- Quarters

- Unit sales of each quarter

- $\quad$ Seasonal effect

\subsubsection{Simple Moving Average}

This statistical technique is mostly used for forecasting demands in the retail industry. But it is an ineffective forecasting technique as it does not take variability in consideration. Here EOQ model is not applied. The technique results for a particular selected product are as under:

Table 1: Steps for Simple Moving Average

\begin{tabular}{c|l|}
\cline { 2 - 2 } Step1 & $\begin{array}{l}\text { Calculate the demand of each product based on } \\
\text { the time period (Quarter) }\end{array}$ \\
\hline Step 2 & \multicolumn{1}{|c}{$\mathbf{F}=\frac{\sum_{i=1}^{n} S_{i-1}}{n}$} \\
& $\begin{array}{l}\text { Use formula: } \\
\text { F= the forecast } \\
\text { S= the sales of the periods. } \\
\text { i, n= the periods. }\end{array}$ \\
\hline \multirow{2}{*}{ Step 3 } & $\begin{array}{l}\text { For each forecast, calculate MAD ( Mean } \\
\text { Absolute Deviation) }\end{array}$ \\
\cline { 2 - 2 }
\end{tabular}

\section{$\Rightarrow$ Forecasting Technique 1: Simple Mloving Average}

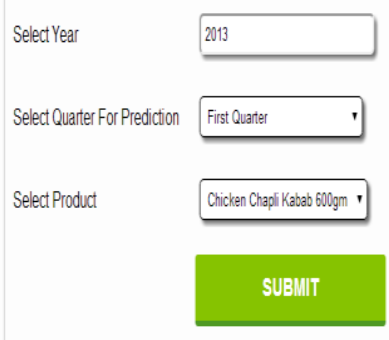

Fig. 2 User interface for simple moving average technique

\section{$\rightarrow$ Chicken Chapli Kabab 600gm}

\begin{tabular}{|lll|}
\hline YEAR & QUARTERS & UnT SALES \\
\hline 1 & 2011 & 158 \\
2 & 2011 & 330 \\
3 & 2011 & 311 \\
4 & 2011 & 190 \\
1 & 2012 & 209 \\
2 & 2012 & 340 \\
3 & 2012 & 309 \\
4 & 2012 & 218 \\
\hline
\end{tabular}

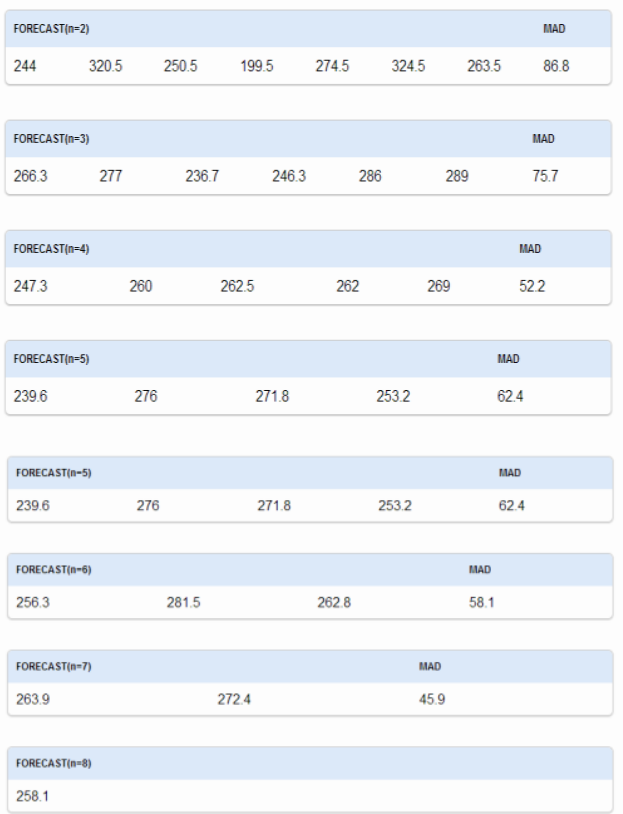

Fig. 3 Demand forecast results for one product for first quarter of year 2013

\begin{tabular}{|l|l|l|l|l|l|l|l|l|l|}
\hline $\begin{array}{l}\text { AVERAGE } \\
\text { DEIIAIID }\end{array}$ & $\begin{array}{l}\text { UNIT PRICE } \\
\text { COST }\end{array}$ & $\begin{array}{l}\text { HOLDIIG } \\
\text { COST }\end{array}$ & $\begin{array}{l}\text { FIX ORDER } \\
\text { COST }\end{array}$ & $\begin{array}{l}\text { LEAD } \\
\text { TIME }\end{array}$ & $\begin{array}{l}\text { TIMES } \\
\text { OROEREO(n) }\end{array}$ & 0 & $\begin{array}{l}\text { OTRHOLDMG } \\
\text { COST }\end{array}$ & $\begin{array}{l}\text { QTR OROER } \\
\text { COST }\end{array}$ & $\begin{array}{l}\text { TOTAL QTR } \\
\text { COST }\end{array}$ \\
\hline 183.5 & 266 & 0.25 & 181.2 & 8 & 1 & 183.5 & 6101.38 & 181.2 & 6282.58 \\
\hline
\end{tabular}

Fig. 4 Estimation of total quarter costs using average demand

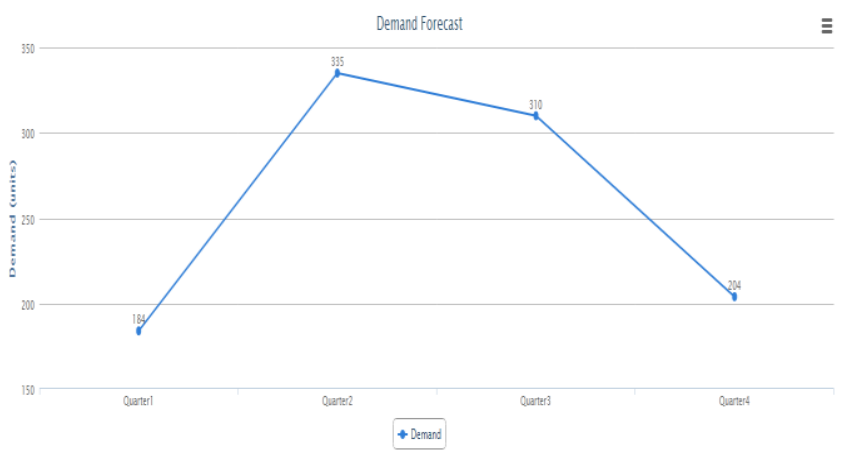

Fig. 5 Graph for demand forecast of one product using simple moving average

\subsubsection{Linear Regression}

This technique is used for forecasting demand. It considers quarters, unit sales to predict demand. Here the demand is not considered as constant from quarter to quarter. Here seasonal index is also used to consider the unpredictable demand.

\section{Table 2: Steps for Linear Regression}

\begin{tabular}{c|l|}
\cline { 2 - 3 } Step1 & $\begin{array}{l}\text { Calculate the demand forecast equation for each } \\
\text { product using formula: } y t=a x i+b\end{array}$ \\
\hline Step 2 & $\begin{array}{l}\text { Calculate seasonal Index=demand/forecast } \\
\text { Expected Forecast= yt*(average seasonal index) }\end{array}$ \\
\hline Step 3 & $\begin{array}{l}\text { Apply Economic Order Quantity Model, and put } \\
\text { forecasted demand in formula: }\end{array}$ \\
\hline
\end{tabular}




\begin{tabular}{l|l|}
\hline & $\mathbf{Q}=\sqrt{\frac{2 * \mathbf{D} * \mathbf{S}}{\mathbf{H} * \mathbf{C}}}$ \\
\hline Step 4 & $\begin{array}{l}\text { Calculate reorder point using formula: } \\
\text { Reorder Point= Demand usage*Lead time (in } \\
\text { days) }\end{array}$ \\
\hline
\end{tabular}

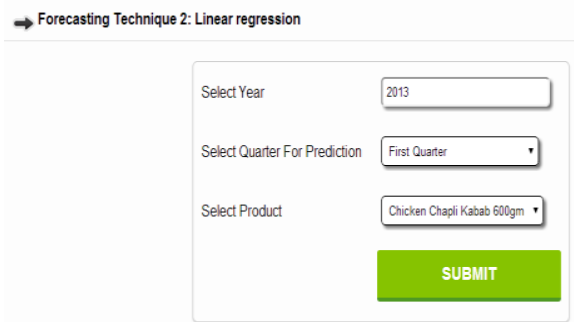

Fig. 6 User interface for linear regression technique The equatonis: $y=23.577+5.0119 * x$

\begin{tabular}{|c|c|c|c|c|}
\hline \multicolumn{5}{|c|}{ Chicken Chapli Kabab 600gm } \\
\hline YEAR & QUaRTERS & UNT SALES & FoRECAST & $\begin{array}{l}\text { SEA SOMALL } \\
\text { WHOEK }\end{array}$ \\
\hline 2011 & 1 & 158 & 240.58 & 0.66 \\
\hline 2011 & 2 & 330 & 245.6 & 1.34 \\
\hline 2011 & 3 & 311 & 250.61 & 1.24 \\
\hline 2011 & 4 & 190 & 255.62 & 0.74 \\
\hline 2012 & 1 & 209 & 260.63 & 0.8 \\
\hline 2012 & 2 & 340 & 265.64 & 1.28 \\
\hline 2012 & 3 & 309 & 270.65 & 1.14 \\
\hline 2012 & 4 & 218 & 275.67 & 0.79 \\
\hline \multicolumn{5}{|c|}{ AVERAGE SEAS SOMAL LNDEXX } \\
\hline 73 & & & 1.31 & \begin{tabular}{l|l}
1.19 & 0.77 \\
\end{tabular} \\
\hline
\end{tabular}

Fig. 7 Demand forecast results for one product for first quarter of year 2013

Economic Order Quantity model is applied to determine optimal order quantity for the selected product.

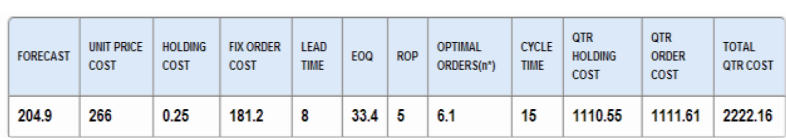

Fig. 8 Estimation of total quarter costs using EOQ Model

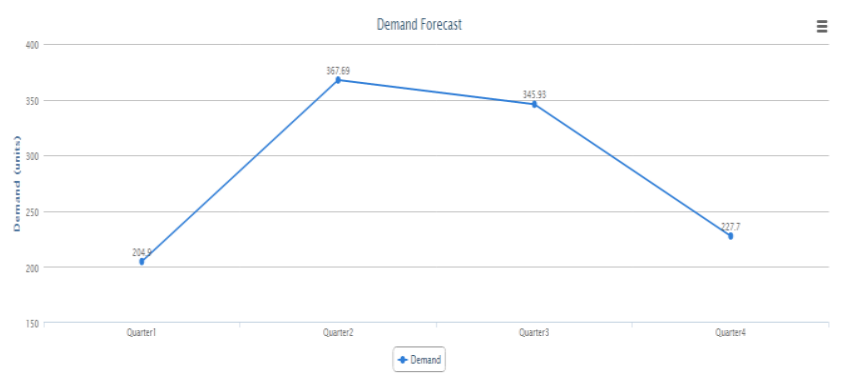

Fig. 9 Graph for demand forecast of one product using linear regression

\subsubsection{Back Propagation}

The algorithm considers quarters, sales and seasonal effect to predict the demand for selected quarter. The algorithm is trained on historical data of products during past two years and gives forecast for the selected quarter of current year for all products.

Table 3: Steps for Back Propagation Algorithm

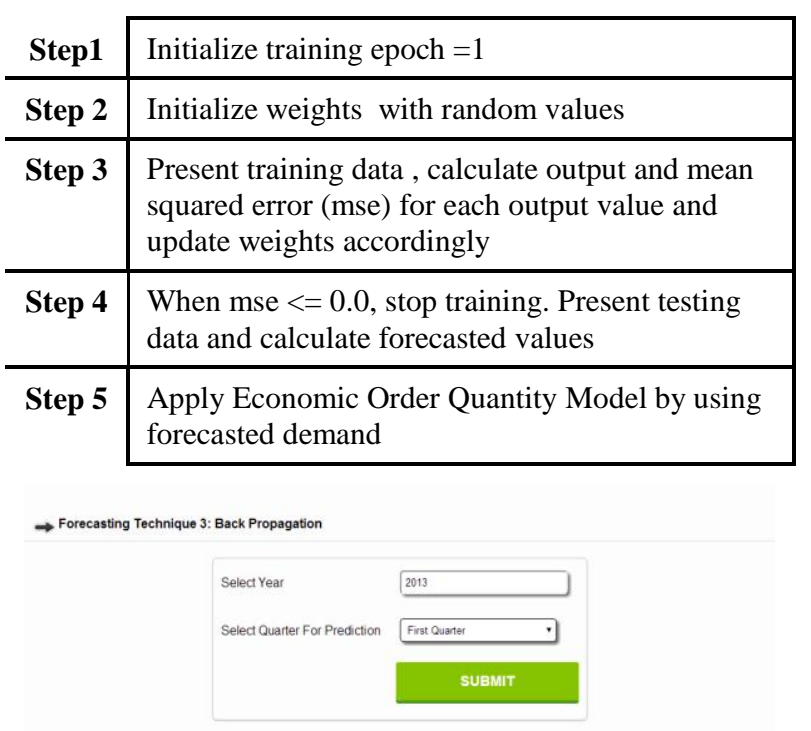

Fig. 10 User interface for back propagation algorithm $\rightarrow 2013$ QUARTER

First epoch Mean Square Error: 0.16900362081994

Network Trained. Thresholl value achieved in 131 terations.

MSE: $5.7056825642099 E-6$

Last epoch Heaan Square Error. 5.7056825642098E-6

\begin{tabular}{|l|l|l|l|l|}
\hline YEAR & OUARTER & UnI SALES & SEASOMAL EFECT & FORECAST \\
\hline 2011 & 1 & 158 & 1.04 & 152 \\
\hline 2012 & 1 & 209 & 1.03 & 202 \\
\hline 2013 & 1 & N/A & 1.03 & 174 \\
\hline 2011 & 1 & 1044 & 1.04 & 1006 \\
\hline 2012 & 1 & 1888 & 1.04 & 1820 \\
\hline 2013 & 1 & N/A & 1.04 & 1641 \\
\hline 2011 & 1 & 1 & 1 & 1 \\
\hline 2012 & 1 & 17 & 1 & 17 \\
\hline 2013 & 1 & N/A & 1 & 9 \\
\hline 2011 & 1 & 1204 & 1.04 & 1161 \\
\hline 2012 & 1 & 1256 & 1.04 & 1211 \\
\hline 2013 & 1 & N/A & 1.04 & 964 \\
\hline 2011 & 1 & 1686 & 1.04 & 1625 \\
\hline 2012 & 1 & 1735 & 1.04 & 1673 \\
\hline 2013 & 1 & N/A & 1.04 & 889 \\
\hline 2011 & 1 & 9 & 1 & 9 \\
\hline 2012 & 1 & 23 & 1.05 & 22 \\
\hline 2013 & 1 & N/A & 1.03 & 29 \\
\hline 2011 & 1 & 928 & 1.04 & 895 \\
\hline 2012 & 1 & 1224 & 1.04 & 1180 \\
\hline 2013 & 1 & N/A & 1.04 & 444 \\
\hline 2011 & 1 & 10 & 1 & 10 \\
\hline 2012 & 1 & 4 & 0.8 & 5 \\
\hline 2013 & 1 & N/A & 1 & 9 \\
\hline & & & & \\
\hline & 1 & 1 & 1 & 1 \\
\hline
\end{tabular}




\begin{tabular}{|l|l|l|l|l|}
\hline 2011 & 1 & 155 & 1.04 & 149 \\
\hline 2012 & 1 & 212 & 1.03 & 205 \\
\hline 2013 & 1 & NA & 1.04 & 299 \\
\hline 2011 & 1 & 268 & 1.04 & 258 \\
\hline 2012 & 1 & 245 & 1.04 & 236 \\
\hline 2013 & 1 & NA & 1.03 & 207 \\
\hline 2011 & 1 & 839 & 1.04 & 809 \\
\hline 2012 & 1 & 964 & 1.04 & 930 \\
\hline 2013 & 1 & NA & 1.04 & 381 \\
\hline 2011 & 1 & 100 & 1.04 & 96 \\
\hline 2012 & 1 & 255 & 1.04 & 246 \\
\hline 2013 & 1 & NA & 1.04 & 367 \\
\hline
\end{tabular}

Fig. 11 Demand forecast results for 12 products for first quarter of year 2013

Economic Order Quantity model is applied to determine optimal order quantity for 12 products.

\begin{tabular}{|c|c|c|c|c|c|c|c|c|c|c|c|}
\hline FORECAST & $\begin{array}{l}\text { UNTT PRICE } \\
\text { COST }\end{array}$ & $\begin{array}{l}\text { HoLDMGG } \\
\text { Cost }\end{array}$ & $\begin{array}{l}\text { FIX OROER } \\
\text { COST }\end{array}$ & $\begin{array}{l}\text { LEAD } \\
\text { TIIEE }\end{array}$ & $E 00$ & ROP & $\begin{array}{l}\text { OPTIMAL } \\
\text { OROERSS(ñ) }\end{array}$ & $\begin{array}{l}\text { CYCLE } \\
\text { TIME }\end{array}$ & $\begin{array}{l}\text { OTR } \\
\text { Holollig } \\
\text { COST }\end{array}$ & $\begin{array}{l}\text { OTR } \\
\text { OROER } \\
\text { COST }\end{array}$ & $\begin{array}{l}\text { TOTAL } \\
\text { QTR COST }\end{array}$ \\
\hline 174 & 266 & 0.25 & 1812 & 8 & 30.8 & 4 & 5.6 & 16 & 1024.1 & 1023.66 & 2047.76 \\
\hline 1641 & 299 & 0.25 & 304.71 & 8 & 115.7 & 36 & 14.2 & 6 & 4324.29 & 4321.77 & 8646.06 \\
\hline 9 & 170 & 0.25 & 160.35 & 4 & 8.2 & 0 & 1.1 & 81 & 174.25 & 175.99 & 350.24 \\
\hline 964 & 150 & 0.25 & 207.56 & 8 & 103.3 & 21 & 9.3 & 10 & 1936.88 & 1936.96 & 3873.84 \\
\hline 889 & 117 & 0.25 & 258.41 & 8 & 125.3 & 20 & 7.1 & 13 & 1832.51 & 1833.41 & 3665.92 \\
\hline 29 & 145 & 0.25 & 105.39 & 4 & 13 & 0 & 2.2 & 40 & 235.63 & 235.1 & 470.73 \\
\hline 444 & 238 & 0.25 & 146.02 & 4 & 46.7 & 5 & 9.5 & 9 & 1389.33 & 1388.28 & 2777.61 \\
\hline 9 & 87 & 0.25 & 132.33 & 4 & 10.5 & 0 & 0.9 & 99 & 114.19 & 113.43 & 227.62 \\
\hline 299 & 100 & 0.25 & 129.24 & 4 & 55.6 & 3 & 5.4 & 16 & 695 & 695.01 & 1390.01 \\
\hline 207 & 1935 & 0.25 & 181.23 & 8 & 12.5 & 5 & 16.6 & 5 & 3023.44 & 3001.17 & 6024.61 \\
\hline 381 & 183 & 0.25 & 50.97 & 8 & 29.1 & 8 & 13.1 & 7 & 665.66 & 667.34 & 1333 \\
\hline 367 & 250 & 0.25 & 207.56 & 8 & 49.4 & 8 & 7.4 & 12 & 1543.75 & 1541.99 & 3085.74 \\
\hline
\end{tabular}

Fig. 12 Estimation of total quarter costs for 12 products using EOQ Model

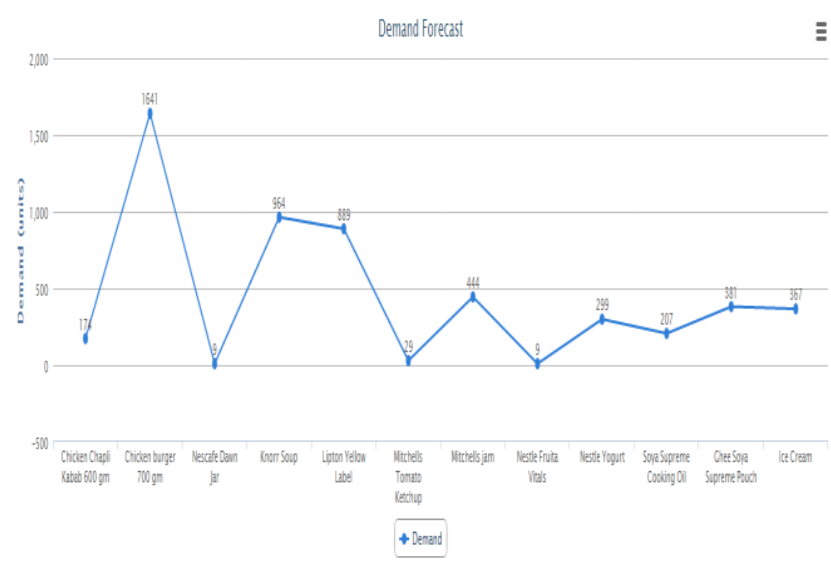

Fig. 13 Graph for demand forecast of 12 products using back propagation algorithm

\subsection{Analyze Sales Transaction Data for Product Shelving by Apriori Algorithm}

The patterns in transactional data will be analyzed using:

- Basket data of each customer

- Unique code for each customer
Table 4: Steps for Apriori Algorithm for Analyzing Transactions

\begin{tabular}{c|l|}
\cline { 2 - 2 } Step1 & Consider basket data of each customer \\
\hline Step 2 & $\begin{array}{l}\text { Generate candidate item sets and define a } \\
\text { minimum support }\end{array}$ \\
\hline Step 3 & $\begin{array}{l}\text { When count of each product becomes less than } \\
\text { minimum support i.e. 1, eliminate that item set }\end{array}$ \\
\hline Step 4 & Get frequent item sets \\
\cline { 2 - 2 } &
\end{tabular}
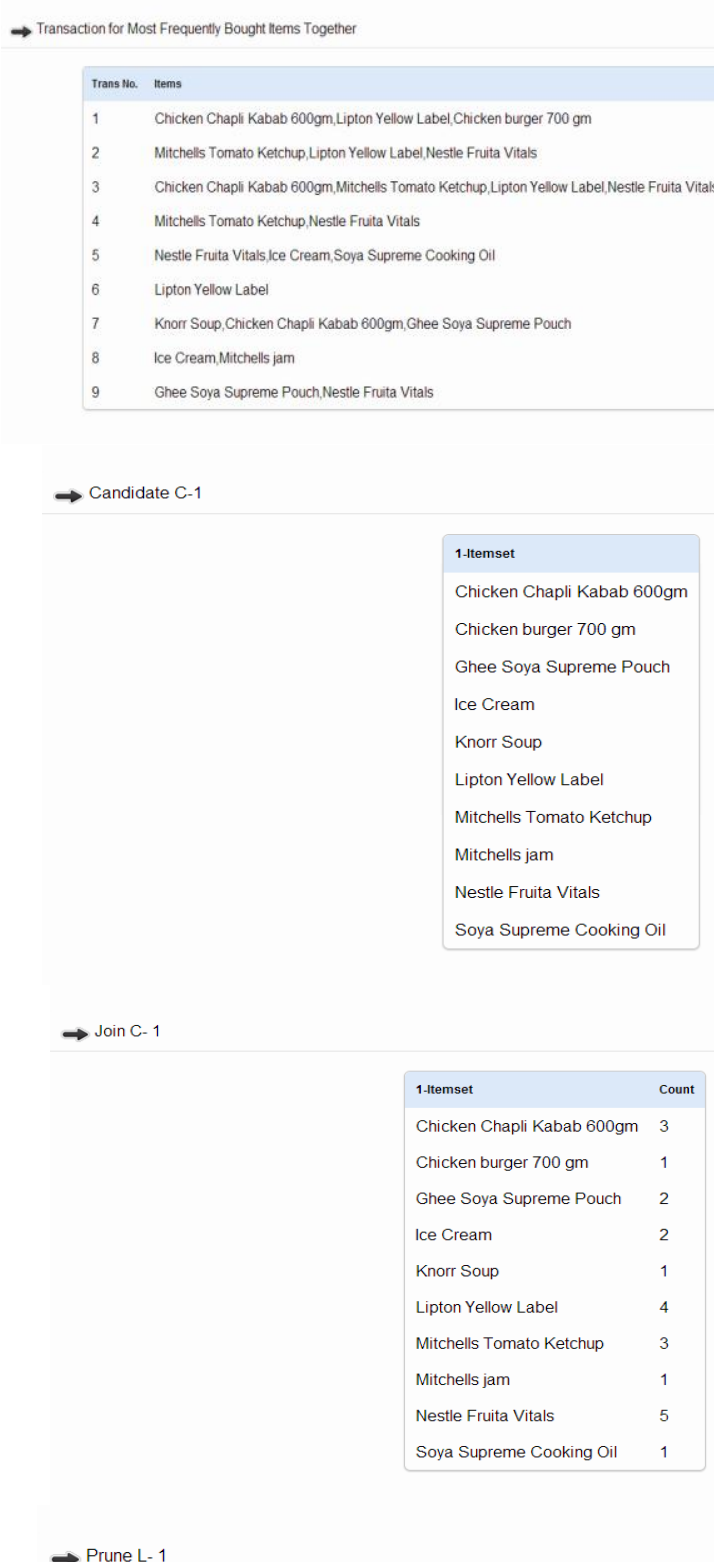

$\Rightarrow$ Prune L-1

\begin{tabular}{|ll|}
\hline 1-ttemset & Count \\
\hline Chicken Chapli Kabab 600gm & 3 \\
Ghee Soya Supreme Pouch & 2 \\
Ice Cream & 2 \\
Lipton Yellow Label & 4 \\
Mitchells Tomato Ketchup & 3 \\
Nestle Fruita Vitals & 5 \\
\hline
\end{tabular}




\subsection{Inventory Categorization(ABC Classification) Based on Product Annual Usage Percentage by K-means Algorithm}

The inventory will be classified into 3 categories based on annual usage $\%$ of products:

- Category A

- Category B

- Category C

Table 5: Steps for K-Means Algorithm for Categorizing Inventory

\begin{tabular}{c|l}
\cline { 2 - 2 } Step1 & $\begin{array}{l}\text { Calculate annual usage }=\text { annual demand *unit } \\
\text { price }\end{array}$ \\
\hline Step 2 & Set number of clusters = 3 (A, B and C) \\
\hline Step 3 & $\begin{array}{l}\text { Calculate average of each cluster and distance of } \\
\text { each value in cluster from the average }\end{array}$ \\
\hline Step 4 & Group values based on minimum distance \\
\cline { 2 - 2 } &
\end{tabular}

$\rightarrow$ Annual Demand and Usage for each item

\begin{tabular}{|c|c|c|c|c|c|}
\hline 10 & ITEM Name & AMNUAL DEMAND & UNIT PRICE & ANNUAL USAGE & ANNUAL USAGE\% \\
\hline 10 & Soya Supreme Cooking Oil & 3820 & 1935 & 7391700 & 61.86 \\
\hline 2 & Chicken burger $700 \mathrm{gm}$ & 6939 & 299 & 2074761 & 17.36 \\
\hline 4 & Knorr Soup & 3827 & 150 & 574050 & 4.8 \\
\hline 5 & Lipton Yellow Label & 4055 & 117 & 474435 & 3.97 \\
\hline 7 & Mitchells jam & 1542 & 238 & 366996 & 3.07 \\
\hline 12 & Ice Cream & 1338 & 250 & 334500 & 2.8 \\
\hline 9 & Nestle Yogut & 2457 & 100 & 245700 & 2.06 \\
\hline 1 & Chicken Chapli Kabab $600 \mathrm{gm}$ & 906 & 266 & 240996 & 2.02 \\
\hline 11 & Ghee Soya Supreme Pouch & 1207 & 183 & 220881 & 1.85 \\
\hline 6 & Mitchells Tomato Ketchup & 76 & 145 & 11020 & 0.09 \\
\hline 3 & Nescafe Dawn Jar & 62 & 170 & 10540 & 0.09 \\
\hline 8 & Nestle Fruta Vitals & 40 & 87 & 3480 & 0.03 \\
\hline
\end{tabular}

Total Annual Usage $=11949059$

Fig. 15 Estimation of annual usage percentage for each product using annual demand and unit price

$\Rightarrow$ Inventory Categorization

Cluster1: Low Level Items $=C$

$4.8,3.97,3.07,2.82 .06,2.02,1.85,0.09,0.09 \cdot 0.03$

Cluster2: Medium level items $=\mathrm{B}$

1736

Cluster3: Most Critical ltems $=A$

61.86

Fig. 16 Inventory (product) categorization into A (most critical), B (medium level) and C (low level) products using k-means algorithm 


\subsection{Supplier Selection based on Given Criteria Through Expert System using Naïve Bayesian Algorithm}

Supplier will be selected on the basis of:

- Item name

- Delivery duration

- Payment duration

- $\quad$ Discount percentage

Table 6: Steps for Naïve Bayesian Algorithm

\begin{tabular}{c|l|}
\cline { 2 - 3 } Step1 & Maintain a knowledge base in database \\
\hline Step 2 & Determine a class variable such as suppliers \\
\hline Step 3 & $\begin{array}{l}\text { For each input attribute (item name, delivery } \\
\text { duration, payment duration, discount), find } \\
\text { probabilities using the data maintained in } \\
\text { knowledge base }\end{array}$ \\
\hline Step 4 & $\begin{array}{l}\text { Multiply the probabilities of input attributes for } \\
\text { each class variable }\end{array}$ \\
\hline Step 5 & $\begin{array}{l}\text { Return the class variable (supplier) with } \\
\text { minimum probability }\end{array}$ \\
\cline { 2 - 2 }
\end{tabular}

$\rightarrow$ FILL CRITERIA

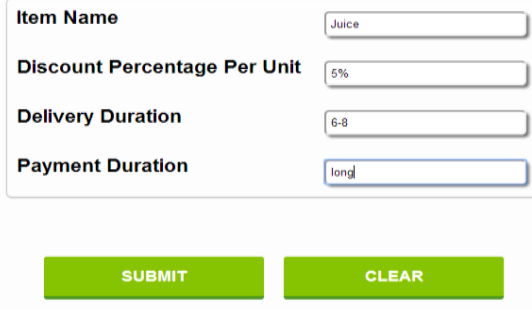

Fig. 17 Interface for filling criteria for a particular purchase order

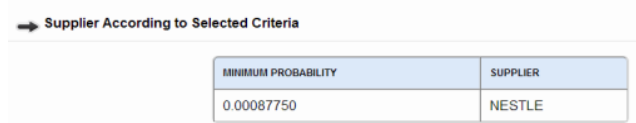

Fig. 18 Applying naïve bayesian algorithm to find suitable supplier for a purchase order

\section{RESULTS}

The application uses HTML, JavaScript, Jquery and CSS for front-end development while PHP for the implementation of back-end development and MySQL is used as database server. As a part of research, a comparative analysis of inventory costs determined using three different techniques (Linear Regression, Moving Average and Back Propagation) is carried out. The historical data, past two years (2011 and 2012) on quarterly basis, of 12 products from a supermarket is collected to determine demand forecast for the current year (2013) and to analyze products sales behavior due to demand.

\subsection{Cost Comparison}

\section{LINEAR REGRESSION}

\begin{tabular}{|l|l|l|}
\hline HOLDWG COST & ORDER COST & TOTAL COST \\
\hline 5214 & 5215 & 10429 \\
\hline 18609 & 18606 & 37215 \\
\hline 1235 & 1235 & 2469 \\
\hline 3634 & 3634 & 7269 \\
\hline 8085 & 8085 & 16170 \\
\hline 885 & 885 & 1770 \\
\hline 5507 & 5504 & 11011 \\
\hline 468 & 469 & 937 \\
\hline 1756 & 1756 & 3512 \\
\hline 23244 & 23222 & 46466 \\
\hline 2608 & 2609 & 5217 \\
\hline 6425 & 6427 & 12852 \\
\hline MOVING AVERAGE & & \\
\hline
\end{tabular}

\begin{tabular}{|c|c|c|}
\hline HOLDING COST & ORDER COST & TOTAL Cost \\
\hline 34331 & 724 & 35055 \\
\hline 118819 & 2436 & 121255 \\
\hline 410 & 1926 & 2336 \\
\hline 4966 & 3320 & 8286 \\
\hline 25683 & 5168 & 30851 \\
\hline 151 & 2464 & 2615 \\
\hline 20993 & 4088 & 25081 \\
\hline 48 & 4193 & 4241 \\
\hline 482 & 4651 & 5133 \\
\hline 93340 & 7244 & 100584 \\
\hline 8062 & 2243 & 10305 \\
\hline 2106 & 9964 & 12070 \\
\hline \multicolumn{3}{|c|}{ BACK PROPAGATON } \\
\hline HOLDIMG Cost & ORDER COST & TOTAL COST \\
\hline 4465 & 4461 & 8926 \\
\hline 17137 & 17139 & 34276 \\
\hline 888 & 888 & 1776 \\
\hline 7506 & 7503 & 15009 \\
\hline 7468 & 7469 & 14937 \\
\hline 724 & 723 & 1447 \\
\hline 4724 & 4730 & 9454 \\
\hline 466 & 464 & 930 \\
\hline 3653 & 3656 & 7309 \\
\hline 19906 & 19873 & 39779 \\
\hline 2261 & 2262 & 4523 \\
\hline 5688 & 5690 & 11378 \\
\hline
\end{tabular}

Fig. 19 Calculation of total costs i.e. holding cost and order cost for linear regression, moving average and back propagation

Table 7: Comparison of Demand Forecast Techniques

\begin{tabular}{|l|l|l|l|l|}
\hline \multicolumn{5}{|c|}{ Demand for Year 2013 Quarter 1 $^{\text {st }}$} \\
\hline Products & $\begin{array}{l}\text { Original } \\
\text { demand }\end{array}$ & $\begin{array}{l}\text { SMA } \\
\text { Forecast }\end{array}$ & $\begin{array}{l}\text { LR } \\
\text { forecast }\end{array}$ & $\begin{array}{l}\text { BP } \\
\text { forecast }\end{array}$ \\
\hline 1 & 176 & 184 & 205 & 174 \\
\hline 2 & 1650 & 1466 & 1748 & 1641 \\
\hline 3 & 9 & 9 & 9 & 9 \\
\hline 4 & 980 & 1230 & 1006.4 & 964 \\
\hline 5 & 900 & 1711 & 982 & 889 \\
\hline 6 & 30 & 16 & 28 & 29 \\
\hline
\end{tabular}




\begin{tabular}{|l|l|l|l|l|}
\hline 7 & 460 & 1076 & 518 & 444 \\
\hline 8 & 9 & 9 & 9 & 9 \\
\hline 9 & 310 & 184 & 300 & 299 \\
\hline 10 & 214 & 257 & 264 & 207 \\
\hline 11 & 390 & 902 & 446 & 381 \\
\hline 12 & 370 & 178 & 429 & 367 \\
\hline
\end{tabular}

From table VII, it is evident that demand forecast using back propagation algorithm comes out to be nearest to the original demand for products in first quarter of year 2013 as obtained from the supermarket. Therefore, back propagation algorithm is efficient for demand forecasting purpose in inventory management as compared to simple moving average and linear regression.

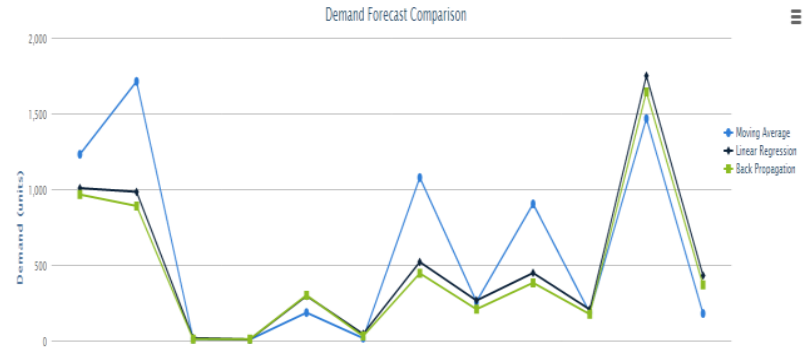

Fig. 21 Graph showing demand forecast comparison among techniques for first quarter of year 2013

Table 8: Cost Comparison

Cost Comparison of Demand Forecasting Techniques

\begin{tabular}{|l|l|l|l|}
\hline Techniques & \multicolumn{1}{|c|}{$\begin{array}{c}\text { EOQ } \\
\text { Model }\end{array}$} & $\begin{array}{c}\text { Total Annual } \\
\text { Costs }\end{array}$ & $\begin{array}{c}\text { Savings } \\
\text { Percentage }\end{array}$ \\
\hline $\begin{array}{l}\text { Simple } \\
\text { Moving } \\
\text { Average }\end{array}$ & No & Rs. 357808 & ------ \\
\hline $\begin{array}{l}\text { Linear } \\
\text { Regression }\end{array}$ & Yes & Rs. 155326 & $57 \%$ \\
\hline $\begin{array}{l}\text { Back } \\
\text { Propagation }\end{array}$ & Yes & Rs. 149745 & $58 \%$ \\
\hline
\end{tabular}

Moving Average is mostly used for forecasting demands in the retail industry. But it is considered to be an ineffective forecasting technique as it incurs high costs due to sales loss and multiple stock outs. Table VIII shows that using simple moving average for demand forecasting purpose results in highest costs per year. Moreover using linear regression for forecasting demand and afterwards using this demand in Economic Order Quantity model to calculate annual costs results in 57\% savings when compared with simple moving average. Using back propagation for forecasting demand and

putting the forecasted demand in Economic Order Quantity model results in 58\% savings when compared with simple moving average. Therefore, it is deduced from the above comparison that the overall inventory costs after applying Economic Order Quantity model are found to be lowest for back propagation algorithm as compared to linear regression and simple moving average.

\section{CONCLUSION AND FUTURE WORK}

This work involves the development of point of sale application with the basic features of managing customers, employees, products, categories, brands, suppliers etc. Moreover it focuses on inventory management and inventory control by using demand forecasting techniques of moving average, linear regression and back propagation. Application of Economic Order Quantity model for reducing the costs related to inventory. It also analyzes the sales data of customers to determine which products must be shelved together to increase sales. It also incorporates the functionality of supplier selection based on given criteria by maintaining knowledge base. Another factor of inventory categorization is handled based on annual usage of products. All these features can make inventory management feasible for a supermarket. Future work can be including the credit and debit card processing functionality in application. Moreover further enhancements are required to consider security issues. The application can include wireless security channel.

\section{REFERENCES}

[1] Karthik Sundararaman, Jinka Parthasarathi, G Subrahmanya VRK Rao, S Nandha Kumar," Baseline Prediction of Point of Sales data for Trade Promotion Optimization", The 2nd International Conference on Communications and Information Technology (ICCIT): Digital Information Management, Hammamet, IEEE 978-1-4673-1950 8/12/\$31.00, 2012.

[2] Numera Tahir, Muhammad Abbas Choudhary," Development of a Decision Support System for Inventory Analysis and Control", IEEE 978-1-61284952-2/11/\$26.00, 2011.

[3] Yunkang Yue, Tiebao Zhang, Xingbing Xu," Analysis on the Effect of Data-mining to Supermarket", The 5th International Conference on Computer Science \& Education Hefei, China. August 24-27, 2010 IEEE.

[4] Qizhi Wu, Aihua Fang, He Gao," A Study on Inventory Cost Reduction Based on Economic Order Quantity Model", The International Conference on Logistics Systems and Intelligent Management, 2010 IEEE.

[5] Pradip Kumar Bala," Decision Tree Based Demand Forecasts for Improving Inventory Performance", International Conference on Industrial Engineering and Engineering Management (IEEM), 2010 IEEE.

[6] Goswami D.N., Chaturvedi Anshu., Raghuvanshi C.S.," An Algorithm for Frequent Pattern Mining Based On Apriori", International Journal on Computer Science and Engineering, Vol. 02, No. 04, 2010, 942-947. 